\title{
Los elementos delimitadores de la discriminación por asociación
}

\author{
The delimiters of discrimination by association
}

\author{
Beatriz Sánchez-Girón Martínez* \\ Master en asesoramiento y consultoría jurídico laboral
}

Recibido: 7/9/2021

Aceptado: 20/10/2021

doi: https://doi.org/10.20318/labos.2021.6490

Resumen: La labor de creación jurisprudencial del TJUE es de vital importancia y tiene presencia en todos los Estados miembros, especialmente en materia de discriminación. A raíz del asunto Coleman apareció la doctrina de la discriminación por asociación, que permitió ampliar el alcance de la discriminación. De esta manera, hoy se reconoce que el principio de igualdad de trato se circunscribe a las personas que poseen unas características concretas protegidas por ley y a otras con las que se relacionan. Sin embargo, continúa siendo un tipo de discriminación jurisprudencial; por eso, es necesario hacer un análisis de la casuística para, finalmente, determinar cuáles son los elementos definitorios de la discriminación por asociación con el fin de clarificarlo y estudiar cómo ha sido y será su aplicación.

Palabras clave: Discriminación por asociación, TJUE, igualdad de trato, directivas, derecho social comunitario.

Abstract: The case law of the CJEU has a critical importance, and it has influenced all the Member States of the EU, especially in the field of equality law. As a result of the judgment of this court in the Coleman case, the discrimination by association allowed the scope of discrimination to be broadened. Due to the gradual application, it is generally said that the principle of equal treatment is limited to people who have specific characteristics protected by law and also to others with which they are related. Nevertheless, it continues to be a type of jurisprudential discrimination and it is not recognized in many provisions. Therefore, it is necessary to make an analysis of the case law in order to determine what are the defining elements of discrimination by association, to clarify this concept and to study how its application has been and will be in the future.

Keywords: Discrimination by association, CJEU, equal treatment, directives, European social law.

\section{Introducción}

Actualmente, la igualdad de trato es un principio jurídico universal inserto en la raíz más profunda de la Unión Europea y de sus Estados miembros. El camino recorrido por nuestra sociedad para alcanzar

"beatriz.sgm@hotmail.com 
la igualdad entre todos los ciudadanos ha sido cuanto menos fructífero en muchos aspectos, y se han alcanzado resultados hasta hace unos años impensables. Sin embargo, todavía existen prejuicios y estereotipos sociales sobre ciertos grupos que obstaculizan alcanzar las metas finales. En diferentes ámbitos de nuestra vida, algunas personas se ven expuestas a vivir situaciones en las que se les brinda un trato más desfavorable. Por esta razón, la norma ha elaborado con gran acierto definiciones sobre los tipos de discriminación que se pueden sufrir especificando qué elementos conforman las mismas, quienes son susceptibles de padecerlas y en que circunstancian pueden darse. Precisamente por ello, este trabajo encuentra su motivación en destacar en la función del Derecho como elemento capaz de dar a todas las personas unas condiciones de igualdad y de remover los obstáculos que se interponen en la lucha por la igualdad efectiva entre todos los ciudadanos, y en todos los ámbitos.

No obstante, el dinamismo de la realidad hace que las definiciones que en un primer momento nacieron como forma de caracterización de la discriminación sean insuficientes. Por eso, han aparecido nuevas formas de discriminación que modifican los elementos que inicialmente configuraban la discriminación para hacer llegar la protección a nuevos supuestos. Una de ellas es el tema inicial del presente trabajo: la discriminación por asociación, la cual se puede definir como "la situación de discriminación que experimenta una persona, no porque posea una característica determinada (...) sino por motivo de su relación con una persona que si posee dicha característica”.

Este trabajo es una investigación jurídica que tiene por objeto definir los elementos de la discriminación por asociación. El derecho tiene un componente sociocultural de gran peso porque se mueve por las exigencias de la sociedad, dando soluciones alternativas a problemas concretos. En este contexto aparece la discriminación por asociación. Su relativa reciente creación exige un estudio profundo de su origen y su paulatina aplicación. Así se podrían concluir cuáles son sus elementos y poder dar, finalmente, respuesta a los problemas que pueden darse en su aplicación.

\section{El origen de la discriminación por asociación}

Sufre una discriminación quien es víctima de un trato desfavorable propiciado por uno de los motivos previstos en la Ley. Estos motivos de discriminación pueden estar contenidos en la norma nacional o internacional, sin olvidar la normativa comunitaria. Gracias a la variedad de casos a los que se ha enfrentado, la jurisprudencia ha concretado cuál es el alcance de esos motivos bajo los que se podría producir una discriminación. Sabemos que la prohibición de discriminación tiene por objeto garantizar el principio de igualdad de trato entre todos los individuos, pero no quiere decir que todas las diferencias de trato sean una discriminación, ya que pueden permitirse si persiguen un objetivo legítimo, con unos medios proporcionales y adecuados para el fin pretendido. Ha sido la pericia jurisprudencial, tanto de Tribunales nacionales como de internacionales, la que ha determinado cuándo algún trato aparentemente desfavorable es objetiva y razonadamente justificado, y cuándo no. $\mathrm{O}$ lo que es lo mismo, se ha precisado con gran acierto cuándo una situación es susceptible de ser discriminatoria, dando lugar a nuevos tipos de discriminación.

\subsection{Origen: El caso Coleman}

En el año 2008, el TJUE resolvía una cuestión prejudicial planteada por el Tribunal inglés Employment Tribunal en relación al alcance de la prohibición de discriminación en la Directiva 2000/78. La respuesta del TJUE, sentencia TJUE Coleman de 17 de julio de 2008, Coleman, C-303/06, ampliaba la noción de discriminación a un supuesto hasta entonces no concebido: la discriminación 
por asociación, también llamada refleja o transferida. Pese a estar vinculada a un caso y a un tipo de discriminación concreto, los criterios de aplicación de la prohibición de discriminación empleados en el supuesto abrían paso a una nueva forma de entender la discriminación, extrapolable a cualquier motivo contenido en la norma.

La señora Coleman prestaba servicios en un despacho de abogados en Reino Unido, pero se vio obligada a abandonar su puesto de trabajo a consecuencia del hostigamiento recibido por el empresario, lo que en Derecho inglés se conoce como unfair constructive dismissal. Este despido se produce cuando la conducta del empresario, contraviniendo las normas y el contrato de trabajo, hace que el trabajador se vea obligado a apartarse del trabajo, por lo que habría que determinar si la conducta empresarial ha sido suficiente para provocar la renuncia del trabajador. Coleman decidió entablar acciones legales argumentando que había sufrido un trato desfavorable en comparación al resto de sus compañeros por el hecho de ser madre de un hijo que sufría una discapacidad. El empresario se había negado de forma sistemática a concederle permisos para fomentar la conciliación laboral y familiar, permisos que otros trabajadores sí tenían; llegando incluso a recibir un trato degradante, consistente en insultos o amenazas al intentar reclamar la concesión de estos permisos. Ante estos hechos, el tribunal inglés (Employment Tribunal) formuló al TJUE cuatro cuestiones prejudiciales para dilucidar si, ante un supuesto como el de Coleman, podría aplicarse la Directiva 2000/78 que se pueden resumir en las siguientes dos preguntas: ¿sería un impedimento para estudiar la posible discriminación el hecho de que quien padece el trato vejatorio no sea la misma persona que sufre el motivo o condiciones determinante de la discriminación? En caso de determinar que no fuese un obstáculo, ¿podría ser un comportamiento discriminatorio el trato menos favorable a un trabajador por el mero hecho de tener un hijo discapacitado?

Con respecto a la primera pregunta, el TJUE realiza una interpretación amplia que no puede tener más que una valoración positiva de la Directiva 2000/78. Dicha directiva contempla expresamente en su artículo primero que su finalidad es establecer "un marco general para luchar contra la discriminación por motivos de religión o convicciones, de discapacidad, de edad, y de orientación sexual en el ámbito del empleo y de la ocupación (...)”. En este caso, es el hijo de Coleman quien sufre una discapacidad, y no ella, lo que podría suscitar dudas acerca de si cabría aplicar la norma europea o si es un supuesto que se encuentra fuera de ella. Pero recalca el TJUE que la norma, de forma expresa dice que se ha de aplicar cuando se dé una situación susceptible de ser discriminatoria por unas determinadas razones (religión, convicciones, discapacidad, edad u orientación) y no solo cuando quienes sufren dicha situación sean una categoría de personas con ciertas características. La Directiva 2000/78 permite que el principio de igualdad de trato garantizado no se circunscriba solo a las personas mismas que sufren discapacidad. Así, sería perfectamente admisible estudiar la posible discriminación en el empleo de la señora Coleman, pudiendo ser víctima de una discriminación por discapacidad pese a que quien sufra la discapacidad sea su hijo y no ella misma. De hecho, cuando la norma prevé presupuestos en exclusiva para personas con discapacidad así lo dice. En efecto, véase cuando se refiere a "ajustes razonables para las personas con discapacidad", en contraposición a la literalidad de su artículo 1 que dice "por motivos de discapacidad". El TJUE apela también a la finalidad de la Directiva, que no es otro que el establecimiento de "un marco general para la luchar (...) en el ámbito del empleo y la ocupación"

En segundo lugar, entiende el TJUE que Coleman sufre una discriminación en tanto que sufre un trato desfavorable por parte del empresario en comparación con el trato que recibieron el resto de sus compańeros, y que esto no se debe más que a la discapacidad sufrida por su hijo, ya que no hay ninguna causa justa para defender la actitud empresarial. Los hechos motivados por el empresario constituyen un supuesto de discriminación, prevista en el artículo segundo de la Directiva, de la cual Coleman es víctima por motivos de discapacidad, pues no es impedimento que sea su hijo quien lo sufra y no ella. 
En virtud de la aplicación del principio de igualdad de trato, el bufete de abogados donde Coleman prestaba servicios, y que ocupa el lugar de parte demandada, es quien tiene la obligación de demostrar que no ha habido discriminación y que el trato dado a la parte actora se debe a razones objetivas. Coleman tan solo tendría que mostrar indicios del trato presuntamente discriminatorio. Por su parte, el Tribunal evaluará si el trato es menos favorable en relación con otras situaciones comparables.

El juzgado inglés que en un primer momento respondió a este litigio explicó que, dentro de la normativa inglesa relativa a la discriminación por discapacidad vigente (Disability Discimination Act 1995), no cabe amparar un supuesto como el de Coleman. Ella alega sufrir discriminación por discapacidad, pero lo cierto es que el texto legal limita la posibilidad de sufrir discriminación por discapacidad a quienes la padezcan.

Las palabras "se produce una discriminación contra una persona discapacitada cuando (...)" permiten excluir a todo sujeto relacionado con quien sufre la discapacidad. Si lo comparamos con el texto de la Directiva, es fácilmente comprensible por qué Coleman se amparó en la normativa comunitaria para obtener la protección merecida. Recordemos que dice el art. 1 Directiva 2000/78:

"La presente Directiva tiene por objeto establecer un marco general para luchar contra la discriminación por motivos de religión o convicciones, de discapacidad, de edad o de orientación sexual en el ámbito del empleo y la ocupación, con el fin de que en los Estados miembros se aplique el principio de igualdad de trato".

No obstante, la normativa inglesa sí parece incluir en otras normas relativas a otros tipos de discriminación a sujetos relacionados con quien directamente sufre el motivo de discriminación, utilizando la misma expresión de la que se sirve la Directiva, "por motivos de", por ejemplo, para el caso de la orientación sexual o de la edad. Esta disparidad de posibilidades ya había provocado que algunos tribunales ingleses se enfrentasen a una compleja realidad por la desigual protección que se ofrecía; y que hubieran intentado corregir hablando de la interconexión de las normas para la igualdad a la hora de su interpretación. Una solución así habría permitido que Coleman encontrase satisfecha su expectativa de protección, pero se habría perpetuado la desigual protección en situaciones que se hubiesen podido dar en casos futuros. De ahí que afirmemos que el TJUE presenta una doctrina innovadora no solo frente a la legislación inglesa, sino ampliable también a todos los derechos nacionales de los Estados miembros. La sentencia Coleman supuso un enorme avance en la protección de los derechos de los trabajadores que pone de manifiesto el modelo inclusivo europeo del que hablaremos más adelante.

\subsection{Implicaciones del caso Coleman}

El efecto más directo de la sentencia Coleman dictada por el TJUE, por supuesto después de la indemnización que nuestra protagonista obtiene de su antigua empresa, es la consolidación del modelo social inclusivo por el que aboga la UE. Todo, sin perjuicio del impacto jurídico que, como veremos a continuación, ha producido la definición de un nuevo estándar de discapacidad: la discapacidad por asociación. La promulgación de la Directiva 2000/78 representó un avance importantísimo para las personas con discapacidad en la lucha por la igualdad de oportunidades porque procura su acceso al empleo y a la formación, obligando al empresario a realizar "ajustes necesarios" en los puestos de trabajo. Al tratarse de una directiva necesita de la transposición de los Estados miembros a señalándose como fecha límite el 2 de diciembre de 2003, haciéndoles partícipes indispensables para acabar con las posibles actitudes discriminatorias que pueda vivir este colectivo, y para ellos 
les permite incluso diseñar acciones positivas, además de ofrecerles un marco jurídico suficiente de protección ante situaciones discriminatorias o constitutivas de acoso. Reino Unido había modificado su normativa nacional para adaptarla a la Directiva: Disability Discrimination Act de 1995 fue modificada en 2003, resultando de esta nueva regulación el artículo 3 que hemos explicado.

Con todo, gracias a la doctrina emanada del asunto Coleman, y en virtud de la aplicación de la Directiva 2000/78, encuentra protección un sujeto desprotegido y estrechamente vinculado con las personas discapacitadas que hasta entonces quedaba desamparado: sus cuidadores. Las tareas de cuidado se refieren a un amplio grupo de trabajos que por regla general se hacen de manera gratuita y sirven para prestar asistencia en su desarrollo a quienes no pueden valerse por sí mismos; como es el caso de niños, ancianos y personas dependientes o discapacitadas. El colectivo que se dedica a estas actividades es especialmente vulnerable porque, aun tratándose de tareas esenciales, se realizan en su gran mayoría sin remuneración o por medio de un contrato laboral que ofrece malas condiciones de trabajo, caracterizado por una remuneración salarial extremadamente baja. Aunque poco a poco este tipo de trabajo se está profesionalizando y mercantilizando, lo cierto es que aún hoy en día es un trabajo que se realiza en el ámbito familiar y que está feminizado, pues son las mujeres sobre quienes recae la asunción de la responsabilidad de cuidar a familiares enfermos o dependientes. La realidad de Coleman encierra una verdad a la que se enfrentan muchas mujeres: el deseo de compaginar el cuidado y su trabajo sin priorizar ninguno sobre el otro. La relación entre trabajo, cuidados y feminización es compleja, y aunque se están diseñando medidas para lograr la conciliación laboral y familiar, lo cierto es que no hay igualdad de género en esta distribución de tareas, hoy todavía asumida por ellas.

Aun cuando en un primer momento se barajó la posibilidad de alegar una discriminación indirecta por razón de sexo, la defensa de Coleman estaba convencida de que lo que realmente se estaba produciendo era una discriminación directa por discapacidad. El argumento inicial se desvanecería fácilmente al constatar que en el despacho de abogados tanto trabajadores como trabajadoras habían conseguido reducir o conciliar su jornada de trabajo. En caso de que se considerase como tal, tampoco habría datos cuantitativos suficientes que sustentasen que se está ocasionando una desventaja particular a las mujeres. Para la defensa de Coleman, detrás toda persona con discapacidad existe alguien que le asiste, y que necesita de una protección jurídica en los mismos términos, lo que se conseguiría ampliado la aplicación de la Directiva 2000/78. El proceso de integración de la UE para que todos los ciudadanos disfruten de las mismas oportunidades de empleo no puede acordarse de quienes sufren discapacidad y olvidarse de quienes les cuidan. Así, gracias al fallo de la sentencia Coleman se consiguió dibujar una protección para los cuidadores ajenos al mercado laboral, pero que desean tener otro tipo de empleo . Si todavía hoy el trabajo de cuidado está más cerca de la esfera doméstica, la noción de discriminación por discapacidad ha ayudado a que tanto mujeres, en su mayoría, como hombres, sean capaces de gozar de una inclusión plena en el mercado laboral.

Además, cabe hacer una puntualización más: ¿qué ocurrirá si en un supuesto como el relatado, quien desease cuidar de su hijo fuese un hombre? ¿cómo se sostendría su defensa? Si solo pensamos en la posibilidad de emplear la discriminación por razón de sexo, no habría manera de inferirles protección jurídica ya que como explica el Exmo. Sr. Magistrado del TSJ de Galicia, Lousada Arochena "el trato se debe realizar en atención al sexo de una persona. Bien utilizando el sexo o una diferencia fisiológica entre los sexos como causa de la diferencia de trato (...) o bien utilizando un perjuicio de género como causa de la diferencia de trato". La única forma de tutelar este supuesto es la discriminación por asociación por razón de discapacidad porque amplia la noción de esta última a familiares, en un primer momento, y después a cualquier otra persona relacionada con la discapacitada. Parece evidente que la negativa empresarial más tiene que ver con las circunstancias personales del discapacitado o dependiente que con el sexo de la solicitante. 
Otro punto que debemos destacar es el respeto que la resolución del asunto Coleman muestra para con las anteriores decisiones del propio TJUE respecto a la noción de discapacidad. Tal y como ha venido diciendo el TJUE, la finalidad de la Directiva 2000/78 es, entre otras, combatir la discriminación en el trabajo y en el empleo por discapacidad. Aunque no se define qué es discapacidad, dos ańos antes a que se dictase la sentencia que estamos estudiando, el TJUE, en el asunto Chacón Navas, clarificó su concepto y dijo que "«discapacidad» se refiere a una limitación derivada de dolencias físicas, mentales o psíquicas y que suponga un obstáculo para que la persona de que se trate participe en la vida profesional". Con este pronunciamiento, la Directiva 2000/78 se excluye de aplicación a los supuestos de enfermedad por mucho que exista una relación causal entre enfermedad y discapacidad. En consecuencia, se excluye a las personas que tienen una enfermedad, y no una discapacidad, porque se entiende que, como regla general, tras un periodo de cura de la enfermedad será posible reanudar la actividad normal. Limitar el concepto jurídico de "discapacidad" sirve para definir con la mayor precisión posible el marco de aplicación de la directiva garantizando altos niveles seguridad jurídica. La intención del TJUE es impedir la ampliación de la Directiva "recurriendo a la analogía a otros motivos distintos de los listados con carácter exhaustivo en su art. 1".

En conclusión, en ningún caso se podría decir que lo que se ha hecho en el caso Coleman es ampliar el campo de aplicación de la Directiva 2000/78 a nuevos motivos no contenidos en el artículo 1 , sino que se han extendido sus efectos, permitiendo que nuevos sujetos padezcan la discriminación. Por lo tanto, la doctrina del asunto Chacón Navas no serviría para desvirtuar la solución en el caso Coleman, ya que no se amplían los motivos tasados y limitados en la ley: el hijo de Coleman era efectivamente discapacitado, pues sufría laringomalacia, broncomalacia y crisis apneas.

Así las cosas, la categoría jurídica de discriminación por asociación nacida de la jurisprudencia asentada en este caso ha cambiado el panorama de la tutela antidiscriminatoria. La interpretación del TJUE amplía la noción de discriminación directa de la Directiva 2000/78 con un criterio acertado por permitir que se discrimine a una persona no por sus características personales, sino por las de otra con las que esa primera se relaciona. Aunque la figura de discriminación por asociación se vinculó inicialmente a la discapacidad y a las personas relacionadas por vínculos de parentesco con quienes la padecen, con el paso del tiempo la discriminación se ha aplicado a otras situaciones más allá de este tipo de discriminación, yendo más allá del ámbito de aplicación de la Directiva 2000/78 y de los vínculos familiares. Ampliar la noción de víctima es necesario para responder a situaciones donde la tradicional concepción de la misma no llegaba, ofreciendo un panorama pragmático para logar la ansiada igualdad efectiva de todos los sujetos históricamente discriminados.

\subsection{La Discriminación por asociación aplicada por el TJUE en otros supuestos}

Desde la elaboración primigénea de la discriminación por asociación, el TJUE ha ido perfilando y confirmando esta jurisprudencia en otros pronunciamientos, aunque, como veremos a continuación, no son excesivamente abundantes.

Existe una normativa europea que obliga a que todos los Estados miembros garanticen que los clientes obtengan información de su consumo eléctrico de una manera periódica . El caso Chez Razpredelenie (Sentencia del TJUE de 16 de julio de 2015, Chez Razpredelenie, C-83/14) donde se aplica la mencionada discriminación por asociación, en un supuesto donde resulta de aplicación la Directiva 2000/43, relativa al principio de igualdad de trato con independencia de su origen racial o étnico. Existe una diferencia de trato injustificada para Nikolova motivada por el origen étnico, como veremos a continuación, en una situación comparable con el resto de 
clientes de las compañías eléctricas pues ella, propietaria de un local en un barrio donde habitaban personas de origen gitano, no podía acceder a su contador eléctrico.

La Directiva 2000/43 tiene un alcance general, a diferencia de la Directiva 2000/78 que se limitaba al ámbito del empleo y de la contratación. Su objetivo es garantizar la igualdad de trato y la protección de todas las personas físicas en el ámbito de la Unión. El TJUE entiende que en un supuesto como este es de aplicación la Directiva 2000/43.

Pese a que Nikolova no es de origen gitano, sufre una desventaja por la relación que existe con el colectivo de origen gitano, ya que es quien habita el barrio donde ella trabaja. Resulta que sin una justificación objetiva y razonada para colocar los contadores seis metros más altos que lo normal, es el mero hecho de que sea un barrio ocupado por personas de origen gitano lo que motiva este trato desfavorable.

Aunque la decisión definitiva corresponde a la jurisdicción búlgara, el TJUE analiza qué entiende como discriminación indirecta porque, aunque Nikolova se siente víctima de una discriminación directa, la Corte Búlgara de Igualdad, entiende que hay una discriminación indirecta. Esto ejemplifica el nutrido debate existente sobre la relación entre ambos tipos de discriminación - Si se colocan los contadores tan altos por el origen étnico de los habitantes del barrio en cuestión, se trata de una discriminación directa. En cambio, si se toma el criterio de colocar los contadores a 7 metros como una política neutra adoptada por la compañía eléctrica por motivos de seguridad jurídica para evitar la manipulación de los mismos y garantizar la calidad del suministro eléctrico, cabría preguntarse si realmente este objetivo es razonable, si es efectiva para la finalidad que pretende, y si pudiese existir algún medio de control menos dañino. En caso de no ser efectivo, no perseguir un fin legítimo, o de poder empelarse otros medios de seguridad menos perjudiciales, Nikolova y cualquier otro vecino de un barrio gitano donde resulta inaccesible el acceso a los datos de consumo eléctrico serían víctimas de una discriminación indirecta por razón de origen étnico. Sin perjuicio de este debate, lo que para el objeto de nuestro trabajo es de consideración es la aplicación de la discriminación por asociación casi de forma automática para confirmar que la Directiva 2000/43 es de aplicación en un supuesto como el que suscita esta controversia, donde quien sufre el perjuicio no es quien tiene un origen racial o étnico diferente, pero sí tiene una relación directa con esta circunstancia que lleva a alegar que se es víctima de una discriminación por asociación.

Un razonamiento similar al seguido en este supuesto se puede ver en el Caso WTG Retail BVBA (STJUE de 20 de junio de 2019, WTG Retail BVBA, C-404/18). No obstante, en esta sentencia el TJUE no habla propiamente de discriminación por asociación ni cita su doctrina, pero aplica una lógica similar a la empleada en el Caso Coleman en la medida en que se amplía la protección, en este caso, contra la discriminación por razón de sexo: la Directiva 2006/54/CE del Parlamento Europeo y del Consejo, de 5 de julio de 2006, relativa a la aplicación del principio de igualdad de oportunidades e igualdad de trato entre hombres y mujeres en asuntos de empleo y ocupación. En realidad, en esta sentencia se entremezclan dos derechos de los trabajadores: el derecho a no ser discriminado en el trabajo y el derecho a no ser perjudicado por el ejercicio de sus derechos. Cuando la señora Vandenbon, gerente de una tienda descubre que su empresa no va a contratar a la señora Hakelbracht por encontrarse embarazada, pese a cumplir con el perfil para dicho puesto, pues así se lo comunica la dirección de Recursos Humanos, no duda en mostrar su oposición ante tal decisión recordando al empresario que la normativa belga prohíbe no contratar a una persona por razón de su embarazo. No cabe duda alguna de que la señora Hakelbracht ha sufrido una discriminación directa por razón de sexo contenida en la Directiva 2006/53 pues recuerda la misma "que el trato desfavorable a una mujer relacionado con el embarazo o la maternidad constituye discriminación directa por razón de sexo", pero ¿y la señora Vandenbon?

La Directiva 2006/54 garantiza modos de protección para todos los trabajadores que puedan sufrir represalias por una discriminación por razón de sexo, refiriéndose a aquellos que defiendan 
a una persona protegida o testifiquen en juicio a su favor. La UE pretende reforzar la garantía de indemnidad de aquellos que denuncien hechos contrarios al Derecho comunitario, como es la denuncia de discriminación por razón de sexo que hace la señora Vandenbon. De la misma manera que ocurría en el caso Coleman, se pone de manifiesto la necesidad de proteger a personas que están vinculadas con personas que pueden sufrir discriminación: bien sea por una relación afectivafamiliar, o bien por una actuación en defensa de sus derechos.

El último pronunciamiento del TJUE en el que se alude a la discriminación por asociación es de enero de 2021 (STJUE de 26 de enero de 2021, C-16/19), que una vez más nos deja ver como gracias a esta doctrina se permiten proteger nuevas situaciones susceptibles de ser discriminatorias. El conflicto llevado ante los Tribunales en este caso es cuanto menos curioso, porque se trata de una posible discriminación por discapacidad entre personas que también que sufren discapacidad. En un hospital polaco tan solo se reconocen complementos salariales a quienes tengan discapacidad reconocida con posterioridad a una fecha fijada por el empresario, quedando fuera de la opción de recibir el mismo quienes tengan una discapacidad reconocida en fecha anterior. El TJUE que pretende ser lo más inclusivo posible y ampliar la tutela discriminatoria comunitaria, utiliza argumentos ya empleados en el caso Coleman porque insiste en la finalidad de la Directiva de "combatir todas las formas de discriminación basadas en la discapacidad". En el caso Coleman se empleaba este razonamiento para defender que el principio de igualdad de trato que se pretende garantizar no se limite solo a las personas que padezcan discapacidad; ahora lo que se avala es que también está cubriendo la discriminación por discapacidad frente a personas que también padecen una discapacidad. Dejar sin protección a los sujetos en un supuesto como este sería vaciar de contenido a la Directiva.

Como vemos, la doctrina de discriminación por asociación que nace bajo la aplicación de la Directiva 2000/78, crece para alcanzar el ámbito de aplicación de otras directivas. Sin duda alguna, en 2008 veía la luz un nuevo tipo de discriminación que aún hoy se va perfilando gracias a la heterogénea casuística. Asimismo, y como prueba irrefutable de la extensión de la noción de discriminación por asociación, la relación paterno filial entre Coleman y su hijo se ha visto sustituida por un criterio más laxo, la simple demostración de un vínculo entre ambos sujetos

\section{La discriminación por asociación y su recepción en España}

Desde que España entró a formar parte de la Unión Europea quedó incluido en el sistema español el sistema de fuentes europeo, tal y como refleja el art. $93 \mathrm{CE}$. Dentro de este sistema de fuentes está la ya mencionada jurisprudencia del TJUE, que por supuesto vincula también a España. Por esta razón, la doctrina emanada del caso Coleman, la doctrina de discriminación por asociación, no dejó indiferentes a los Tribunales espańoles. Los criterios interpretativos empleados en ese asunto fueron imitados y trasladados a otros casos en nuestro país, dejando constancia de la primacía de las decisiones interpretativas del TJUE, como veremos a continuación.

Sin embargo, un gran paso en la asimilación de la discriminación por asociación en el Derecho español se dio en el año 2013 con la promulgación del Real Decreto Legislativo 1/2013, de 29 de noviembre, por el que aprueba el Texto Refundido de la Ley General de derechos de las personas con discapacidad y de su inclusión social. Quiero recalcar que esta norma es innovadora, ya que por primera y única vez recoge textualmente este tipo de discriminación. Si bien ya se había empleado antes en una resolución judicial del STSJ de Cataluña del 23 de junio de 2011, no de sentencia 4456/2011. El artículo segundo de la ley define discriminación por asociación sosteniendo que tal "existe cuando una persona o grupo en que se integra es objeto de un trato discriminatorio debido a 
su relación con otra por motivo o por razón de discapacidad”. Esta ley evidencia que la lucha contra la discriminación por discapacidad no ha de englobar únicamente a las personas con discapacidad, porque si así fuese, muchos otros sujetos vinculados con su cuidado quedarían desamparados.

Los argumentos seguidos por el TJUE en Coleman no ha sido empleado por nuestros tribunales en muchos casos, ya que corroborar la existencia de todos los requisitos necesarios para su consideración no siempre es tarea fácil. Estudiar la prohibición de la discriminación y la discriminación por asociación desde una óptica nacional se hace más interesante en la medida en que el acervo normativo espańol nos es más cercano y se ha visto modificado para adecuarse a la normativa comunitaria.

El principio de igualdad de trato en el sistema español se ha completado con un desarrollo normativo abundante, motivado en gran medida por las demandas de los diferentes colectivos que reclaman protección. Con excepción de la mencionada Ley 1/2013, la discriminación por asociación no se ha reconocido en otras leyes nacionales directamente, pero eso no ha excluido a los tribunales de su aplicación. La norma española utiliza "una formula amplia", prohibiendo la discriminación en los mismos términos que las Directivas europeas, "por razón de”.

En la STSJ de Cataluña, de 23 de junio de 2011 (no 4456/2011), se apela, salvo error por mi parte, por primera vez a la discriminación por asociación en un supuesto que guarda mucha similitud con el caso Coleman. En este caso, la trabajadora solicita una ayuda para cuidar a su marido que sufre una discapacidad, y presenta indicios discriminatorios alegando que ha sido la solicitud de este permiso lo que realmente ha motivado el despido. El TSJ, refiriéndose específicamente al caso Coleman, explica que esta doctrina ha dejado sentado que "la prohibición de discriminación (...) no se circunscribe exclusivamente a aquellas personas que sean ellas mismas discapacitadas". Si en el caso Coleman el TJUE protegió a la madre de un hijo discapacitado por sufrir un trato peor que el resto de sus compañeros, ahora también se habrá de proteger a la mujer trabajadora despedida por haber solicitado el permiso para cuidar de su cónyuge discapacitado porque también hay una discriminación por discapacidad y por asociación.

$\mathrm{Al}$ igual que el TJUE ha ido ampliando los limites iniciales de la doctrina Coleman a nuevos supuestos, los Tribunales españoles también han procedido de esta manera, extendiendo la discriminación por asociación a otros posibles motivos más allá de la discapacidad, y a otros tipos de relaciones además de los vínculos familiares. Una trascendental sentencia es la STSJ de Galicia de 2 de agosto de 2017 (ECLI:ES:TSJGAL:2017:5511), que reconoce la doctrina de la discriminación por asociación con causa en la vulneración del derecho a la libertad sindical. La libertad sindical es un derecho fundamental reconocido en el art. 28.1 CE y su contenido se refiere, además del ejercicio propio de las facultades sindicales, a participar y desarrollar en libertad el proceso de las elecciones sindicales en una empresa.

Habida cuenta de la posible vulneración del derecho a la libertad sindical, el TSJ gallego además reconoce que es un supuesto de discriminación refleja o por asociación al igual que ocurre en el caso Coleman, donde quien sufre tal trato discriminatorio no es propiamente una persona protegida por la norma. El trabajador al no ser sindicalista no quedaría protegido por el colectivo al que se refiere la libertad sindical, pero, continúa la sentencia explicando que existe una relación evidente entre los miembros de una mesa electoral y la realización del ejercicio efectivo de la libertad sindical porque, de no quedar protegidos, este libre ejercicio quedaría amenazado

En aras de proteger el derecho fundamental a la libertad sindical, la doctrina Coleman es aplicada por el TSJ de Canarias (STSJ Canarias de 29 de agosto de 2019, ECLI:ES:TSJICAN:2019:2116) de nuevo en un supuesto en el que a quien se está discriminando es a la mujer de un sindicalista en activo, que es despedida sin causa justa alguna. No es ella la sindicalista, pero el Tribunal observa indicios suficientes para declarar que ella se está llevando un trato desfavorable e injustificado fruto de la acción reivindicatoria de su marido. 
La doctrina Coleman también se ha referido a supuestos de discriminación por asociación y discriminación por razón de sexo, basadas en los prejuicios sociales y culturales asociados al sexo, asimiladas por nuestra sociedad. En España, la LOI la que no solo prohibió la discriminación por razón de sexo, sino que lo configuró como un principio al que está sometido el ordenamiento jurídico en su totalidad. Al amparo de esta norma se han elaborado nuevos tipos de discriminación, donde por supuesto aparece la discriminación por asociación.

En la STSJ de Galicia de 13 de abril de 2018 (ECLI:ES:TSJGAL:2018:2484) se analiza un supuesto de acoso sexual sufrido por una trabajadora, cuyos efectos perjudiciales se extienden también a su marido, empleado de la misma empresa. Su acoso es fruto de la demanda planteada por su esposa alegando ser víctima de un acoso sexual ante la inactividad de la empresa para frenarlo, acentuado por la sentencia estimatoria que ella obtuvo. En consonancia con la doctrina Coleman, el TSJ reconoce que él padece "un acoso discriminatorio sexista atendiendo a la conexión de la situación laboral del trabajador demandante con la discriminación sexista sufrida por su esposa”.

Otro ejemplo más de la doctrina Coleman en supuestos de discriminación por razón de sexo se ve en la STC 71/2020 de 29 de junio (ECLI:ES:TC:2020:71), donde además queda bastante clara la diferencia entre la discriminación por asociación y la discriminación indirecta. El supuesto de hecho versa sobre la denegación de un permiso de dos días por familiar hospitalizado a una trabajadora para cuidar de su hermana ingresada por parto. La denegación de la empresa, amparado en su Convenio Colectivo, se sustenta en que el embarazo no está cubierto por el mismo, por no tratarse de una enfermedad y que solo si la hospitalización ha sido provocada por una enfermedad se tendrá derecho al permiso. El TC considera que la exclusiva referencia a los supuestos en los que la hospitalización ha de serlo por enfermedad provoca una discriminación hacia las mujeres, ya que son ellas quienes dan a luz, y por lo tanto quienes puedes ser hospitalizadas por motivos ajenos a la enfermedad. Pero, determinar ante qué tipo de discriminación estamos, si es discriminación directa, indirecta u otro, no es tarea sencilla. No existe una norma aparentemente neutra que cause un daño en el colectivo de las mujeres, pues explica el TC que la norma que excluye a la hospitalización por parto no es neutra, sino que es claramente discriminatoria para el colectivo femenino; descartando así la discriminación indirecta. Tampoco se puede defender una discriminación directa porque la actora, la demandante del permiso, no está siendo directamente discriminada por pertenecer a un colectivo vulnerable como las mujeres, y ni si quiera es ella misma quien está embarazada; el hecho de que ella sea mujer es irrelevante. No queda así más solución que acudir a la doctrina de discriminación por asociación, porque a quien se está tratando desfavorablemente es a los trabajadores que solicitan el permiso para cuidar de un familiar, en este caso una mujer que ha dado luz. Por lo tanto, es ella quien posee un motivo discriminatorio, pero el trabajador solicitante del permiso quien sufre el perjuicio al obtener su denegación.

Existe una sentencia reciente donde se ha visto discriminación por asociación en un supuesto en que el también hay discriminación indirecta. Esto ha sido posible gracias a aplicar el principio de igualdad entre hombres y mujeres, que es transversal al sistema de seguridad social, y que muchas veces perjudica a las mujeres que tradicionalmente han estado alejados del mercado de trabajo. En este caso, STS 79/2020 del 29 de enero de 2020 (ECLI:ES:TS:2020:416), la parte actora es una hija que reclama el reconocimiento de una pensión por muerte y supervivencia tras el fallecimiento de su madre. Los requisitos para su reconocimiento se encuentran en el art. 226 LGSS, y dice en su apartado segundo "se reconocerá derecho a pensión a los hijos o hermanos de beneficiarios de pensiones contributivas de jubilación e incapacidad permanente, en quienes se den, en los términos que se establezcan reglamentariamente (...)”. ¿Qué ocurre con quienes son hijos de no beneficiaros de estas pensiones, si no de las pensiones SOVI (seguro obligatorio de vejez e invalidez)? Recordemos que las pensiones SOVI son un régimen de pensiones a extinguir que cubre contingencias como la vejez, 
viudedad e invalidez; y que está muy feminizado porque son en su mayoría mujeres las beneficiarias. Tras el fallecimiento de su progenitora, la parte actora reclama la pensión de muerte y supervivencia, que se le deniega por no ser la causante de la misma titular de una pensión de jubilación o incapacidad contributiva. Un estudio de la norma de Seguridad Social poniendo de relieve el enjuiciamiento de género permite resolver los casos judiciales asumiendo que existe una subordinación estructural de las mujeres hacia los hombres y para acabar con esta lacra hay que garantizar que tanto hombres y mujeres gocen de las misas oportunidades. Así, se llega a la conclusión por el TS de que existe un impacto negativo en la consecución de estas mismas oportunidades ya que la mayoría de pensionistas SOVI son mujeres, lo que hace que no reconocer a sus descendientes la pensión de muerte y supervivencia tenga un impacto negativo de género. Se trata de una discriminación indirecta: un criterio aparentemente neutro (reconocer las pensiones de supervivencia y muerte a quienes sean descendientes de pensionista de jubilación o invalidez contributiva), que afecta a las mujeres de forma negativa como hemos explicado. Sin embargo, aquí se cumple además una discriminación por asociación: el impacto de género de la exclusión de las pensiones SOVI para el acceso a las prestaciones a favor de familiares tiene su manifestación en que se ven privados de recibirlas los descendientes. Sin embargo, quienes sufren realmente la consecuencia negativa son sus descendientes, que carecen del derecho a este tipo de prestaciones. Un criterio neutro coloca a las mujeres en una situación particular y perjudicial, pues en datos cuantitativos sabemos que reciben pensiones SOVI en mayor proporción que los hombres, al no reconocerlas como sujetos causantes de las pensiones por muerte y supervivencia; pero, los efectos se trasladan a sus descendientes con independencia del género.

\section{Algunas consideraciones sobre la discriminación por asociacion}

Tras un recorrido sobre la casuística y los supuestos en los que se ha hecho uso de la discriminación por asociación, podemos proceder a realizar unas meditadas reflexiones acerca de qué ha supuesto, y qué puede llegar a suponer, el reconocimiento de este tipo de discriminación.

En primer lugar, ha quedado claro que el fenómeno de la discriminación es dinámico y cambiante, al igual que lo es el Derecho. El Derecho forma parte de todos los momentos de nuestra vida, incluso antes de nuestro nacimiento y hasta en las relaciones que dejamos mortis causa, porque preside las relaciones sociales humanas, ofreciendo respuestas a los nuevos problemas que paulatinamente van apareciendo. El Derecho cambió drásticamente desde que las revoluciones del siglo XVII en Europa y América proclamasen la igualdad como un principio, reconociendo la dignidad humana y otros derechos fundamentales. Pero esto fue tan solo el comienzo de un largo camino que se ha ido construyendo sobre estos cimientos para contestar a las nuevas demandas sociales, porque el progreso del Derecho no se entiende sin el progreso de la sociedad. Prueba de ello es la evolución y ampliación que ha sufrido la noción de igualdad a lo largo del tiempo. Originariamente, se trataba de un concepto limitado: igualdad ante la ley, como forma de aplicar la ley por igual a todas las personas. Ahora, se busca lograr una igualdad en la ley, sin privilegios, que garantice a todos los sujetos el mismo número de oportunidades, requiriendo así una mayor implicación de los sistemas normativos para que ofrezcan una tutela antidiscriminatoria acertada y completa.

En otro orden de cosas, la concepción de discriminación ha evolucionado paulatinamente. Basta con reparar en el art. 17 del ET, testigo de cómo el tiempo y el progreso social han hecho de él un artículo completo en la prevención de motivos discriminatorios que pueden darse en el ámbito laboral. Si en el año 1995 prohibía la discriminación por razón de sexo, origen, raza, estado civil, condición social, religión e ideas políticas; en el año 2003 se ampliaba a circunstancias de etnia, convicciones y orientación sexual; y en el año 2010 se promulgaba la actual redacción que incluye 
la discriminación por razón de edad, discapacidad y habla de orientación y condición sexual. Esto ha sido posible gracias al impulso de la UE. En el año 2000 se aprobaban dos directivas: Directiva 2000/43/CE del Consejo, de 29 de junio de 2000, relativa a la aplicación del principio de igualdad de trato de las personas independientemente de su origen racial o étnico, y la Directiva 2000/78 que, como ya bien sabemos, establece un marco general para la igualdad de trato y la ocupación. Estas directivas y las leyes nuevas o modificaciones que se hacen en la norma española para su trasposición, responden a la necesidad de crear un mercado de trabajo totalmente integrado. Desgraciadamente, los datos revelan que las personas con discapacidad, de mayor edad y las mujeres tienen más altas tasas de desempleo, por ejemplo. Asimismo, se pretende acabar con la discriminación por origen ya que estas personas en no pocas ocasiones tienen que enfrentarse a actitudes xenófobas o racistas, alejadas de la cohesión social y del desarrollo que pretende lograrse en una sociedad moderna.

Actualmente, el principio de igualdad se interpreta en una acepción moderna que lo hace estar conformado no solo por la prohibición de discriminación, sino también por la búsqueda de la igualdad efectiva que implica remover los obstáculos discriminatorios.

No son solo los motivos que pueden provocar discriminación son los que han crecido en los últimos tiempos, sino que las formas de manifestarse lo han hecho también. En las leyes citadas a lo largo del trabajo, donde se recogen las discriminaciones prohibidas, aparece la definición de discriminación directa como manifestación icónica de la misma: recibir un trato diferente y desfavorable por un motivo prohibido. También aparece la discriminación indirecta, de creación jurisprudencial inicialmente, ahora reconocida en la normativa europea; al igual que el acoso, como una forma de discriminación integral. Así, se han elaborado nuevas tipologías de discriminación con el objetivo de ampliar la tutela antidiscriminatoria a sujetos en un principio no incluidos, en un principio, en el ámbito subjetivo de las formas tradicionales de discriminación, y por eso son formas son especialmente sensibles al efecto lesivo que produce la discriminación. Son ejemplo de ellas: la discriminación por apariencia, la discriminación múltiple y la discriminación por asociación.

En cualquier otro caso, también ha quedado reconocido una vez más la labor hermenéutica y nomofilactica del TJUE, en cuanto a la interpretación de los textos y normas que forman el Derecho europeo, garantizando que se haga de una manera uniforme para que no se vulnere el principio de igualdad ante la ley. Al reducir los criterios interpretativos con los que una norma puede ser interpretada, sirviendo de guía a los tribunales nacionales de los Estados comunitarios, aumenta la seguridad jurídica.

La forma que tiene el TJUE a la hora de desarrollar esta función de vigilar la eficacia de la norma, y de creación de la misma, es básicamente a través de las cuestiones prejudiciales (art. 267 TFUE). Un juez nacional plantea al TJUE una pregunta sobre cómo interpretar una norma europea en un caso al que se está enfrentando. En algunas ocasiones, la respuesta del TJUE ha consistido en proponer pautas, tal y como venimos señalando en este trabajo, para interpretar una norma europea que, a pesar de que proceden de la aplicación de la misma a un caso concreto, son extrapolables a una infinidad de situaciones. La doctrina de discriminación por asociación forma parte de este supuesto, porque cuando Coleman planteó su caso ante el Tribunal de Luxemburgo, principalmente se pretendía, fundamentalmente, dar respuesta a su caso concreto y obtener un resultado favorable, aunque subsidiariamente se elaborase una nueva forma de explicar una manifestación de la discriminación.

La jurisprudencia comunitaria construye este tipo de discriminación que se ha completado con más pronunciamientos. Bajo la influencia del Derecho de la UE, en los ordenamientos jurídicos de los Estados miembros también se ha manejado este concreto y se ha contribuido a su configuración, tal y como se ha visto que en la aplicación del mismo por los Tribunales españoles. A raíz de la sentencia Coleman podemos decir que "el principio de igualdad de trato no se circunscribe, 
única y exclusivamente, a las personas que padezcan ellas mismas una discapacidad, sino que también incluye a las que por tener alguna relación con ellas son tratadas de un modo discriminatorio". Asimismo, y tras la extensión del concepto, podemos afirmar que la discriminación por asociación es la discriminación directa o indirecta que una persona puede sufrir por su relación con otras.

Podemos concluir cuáles son los elementos de la discriminación por asociación y cuáles son sus dificultades conceptuales:

(i) Que el supuesto de hecho caiga bajo el ámbito de aplicación de alguna norma que otorgue una tutela antidiscriminatoria. Esto es, se exige que al supuesto de hecho pueda aplicarse una norma porque queda amparado en su ámbito de aplicación material. O lo que es lo mismo, que la situación que se está enjuiciando haya sido prevista por el legislador. Como es lógico, se tratará de una norma, una directiva, una norma de trasposición, o cualquier otra, que tenga como objetivo luchar contra la discriminación para aplicar el principio de igualdad de trato. Para ello, ha de definir conductas susceptibles de discriminación y personas vulnerables a sufrirlas; pero además puede limitarse a un ámbito concreto en lugar de ser aplicación general. Es el caso de la Directiva 2000/78 o la Directiva 2006/54 que se circunscribe al ámbito del empleo y de la ocupación, frente a, por ejemplo, la Directiva 2000/43 que en su artículo tercero enumera una serie de ámbitos donde cabe apelar a esa norma.

(ii) Que, a consecuencia de un acto u omisión, un sujeto sufra una particular desventaja en una situación comparable con otros sujetos. El núcleo esencial de toda discriminación es la posición de desventaja que vive una persona respecto de otra, que bien puede proceder de un acto concreto que provoca una situación de inferioridad a la posible víctima; o bien puede ser de una provisión o condición aparentemente neutral, pero que afecta negativamente a un grupo de personas con algún rasgo común situándolo en una posición social o jurídica inferior. Véase STJUE 17 de julio de 2008 (C-303/06, Coleman) cuestión perjudicial segunda: “¿protege la Directiva 2000/78 a los trabajadores que, aun sin estar ellos mismos discapacitados, reciben un trato menos favorable o sufren acoso por su vinculación a una persona discapacitada?”. Para que haya discriminación se requiere que exista una situación comparable, que existe una persona en una situación similar con la que elaborar unos estándares de equivalencia.

(iii) Que dicha práctica, criterio o disposición, haya estado motivado y este intimamente relacionado con la circunstancia o características personales protegidas en la ley; y que no tenga justificación alguna. Si se trata de discriminación directa, ya se ha visto que la actuación está fundamentada principalmente en la pertenencia al grupo protegido de la víctima, de lo cual se puede deducir que, si la víctima no perteneciese a ese grupo de personas con categoría protegida, es altamente probable que no hubiese sufrido ninguna discriminación. Sin embargo, no ocurre de esta manera en el caso de la discriminación indirecta, donde la práctica neutra guarda relación con estos grupos de personas protegidas porque son quienes se ven afectados negativamente por ella. Las razones o causas de las discriminaciones, siempre, están enumerados en una en las diferentes norma, europeas o españolas, conformando una lista cerrada. Se ha visto la posibilidad de discriminación por asociación en supuestos de diversa naturaleza: discriminación por discapacidad (asunto Coleman C-303/06 y STSJ de Cataluña, 4 de julio de 2011), por etnia u origen (asunto Chez Razpredeleine C- 83/2014), por razón de sexo (asunto WTG Retail BVBA C- 404/18 o STSJ Galicia, de 13 de abril de 2018) libertad sindical (STSJ Galicia, de 2 de agosto de 2017 o STSJ Canarias de 29 de agosto de 2019). 
No obstante, en determinados casos se ha permitido la diferencia de trato, siempre que se sustente sobre una finalidad legítima y haya elegido unos medios adecuados para su consecución, proporcionales y necesarios. Por ejemplo, las directivas en el ámbito del empleo y la ocupación dicen que se permitirá una diferencia de trato si lo es de acuerdo a los "requisitos profesionales esenciales" Esta finalidad suele extralimitarse del interés particular de un individuo, por ejemplo, de un empresario, en la toma de sus decisiones. Aunque los Estados tienen un cierto margen de discrecionalidad, los tribunales tienen a proteger el bien común frente al individual, y a intentar prohibir toda diferencia de trato que no esté ampliamente justificada por una finalidad beneficiosa en el sentido más amplio de la palabra.

(iv) Que el sujeto que sufre la discriminación no sea la misma persona que padezca o tenga la circunstancia o caracteristica protegida por la ley. Una vez que podemos concluir que se cumplen estos tres requisitos generales para encontrarnos frente a una discriminación prohibida por ley, se ha de estudiar la especificidad de la discriminación por asociación, que es precisamente esta duplicidad de sujetos: el protegido legalmente y el discriminado. $Y$ es que en estos supuestos estamos ante un hecho que no podríamos catalogar como discriminación directa, indirecta o acoso en los términos que propiamente exige la ley porque se da un cuarto requisito adicional: la diferencia entre la víctima del trato discriminatorio y el sujeto que padece la razón que motiva la discriminación. Me parece muy ilustrativo para esta explicación usar el término discriminación por irradiación o refleja. Ambos términos han sido utilizados por los Tribunales en algunas ocasiones, por ejemplo, en la reciente STSJ de Galicia de 25 de junio de 2020, como sinónimo de discriminación por asociación que deja claro la esencia de la misma: dar protección a un sujeto que no debería estarlo por no formar parte de un colectivo vulnerable, gracias al efecto de irradiación que se produce trasladando al primero la protección del segundo.

Se trata de una relación triangular entre:

a) El sujeto A que provoca una situación desfavorable hacia otro sujeto, bien sea por un acto discriminatorio o por uno neutro con efectos discriminatorios.

b) El sujeto $B$ que sufre la discriminación.

c) El sujeto $\mathrm{C}$ que pertenece a un grupo vulnerable causante de dicha discriminación.

Estos tres sujetos, o colectivos, vértices de una relación triangular que se forja entre ellos hace que se formen tres tipos de relaciones entre ellos, porque de otro modo, no podríamos alegar ningún tipo de discriminación. La relación entre $\mathrm{B}$ y $\mathrm{C}$ es la piedra angular que sirve de cimiento para construir una discriminación por asociación, pero es también su talón de Aquiles, ya que sin relación entre el sujeto discriminado y el protegido de ninguna manera se podría hablar de discriminación por asociación.

(v) Que exista una relación entre el sujeto perteneciente a un colectivo vulnerable y el sujeto demandante de tutela antidiscriminatoria. En la discriminación por asociación el entramado de relaciones entre los tres sujetos implicados puede quedar dibujado así:

La discriminación por asociación es la que padece una persona que sufre un trato menos favorable que otras personas no pertenecientes a un colectivo protegido, pero que se produce por estar vinculado con el colectivo protegido. A esta persona también se le ha de dar la misma protección 


\section{Esquema de la discriminación por asociación}

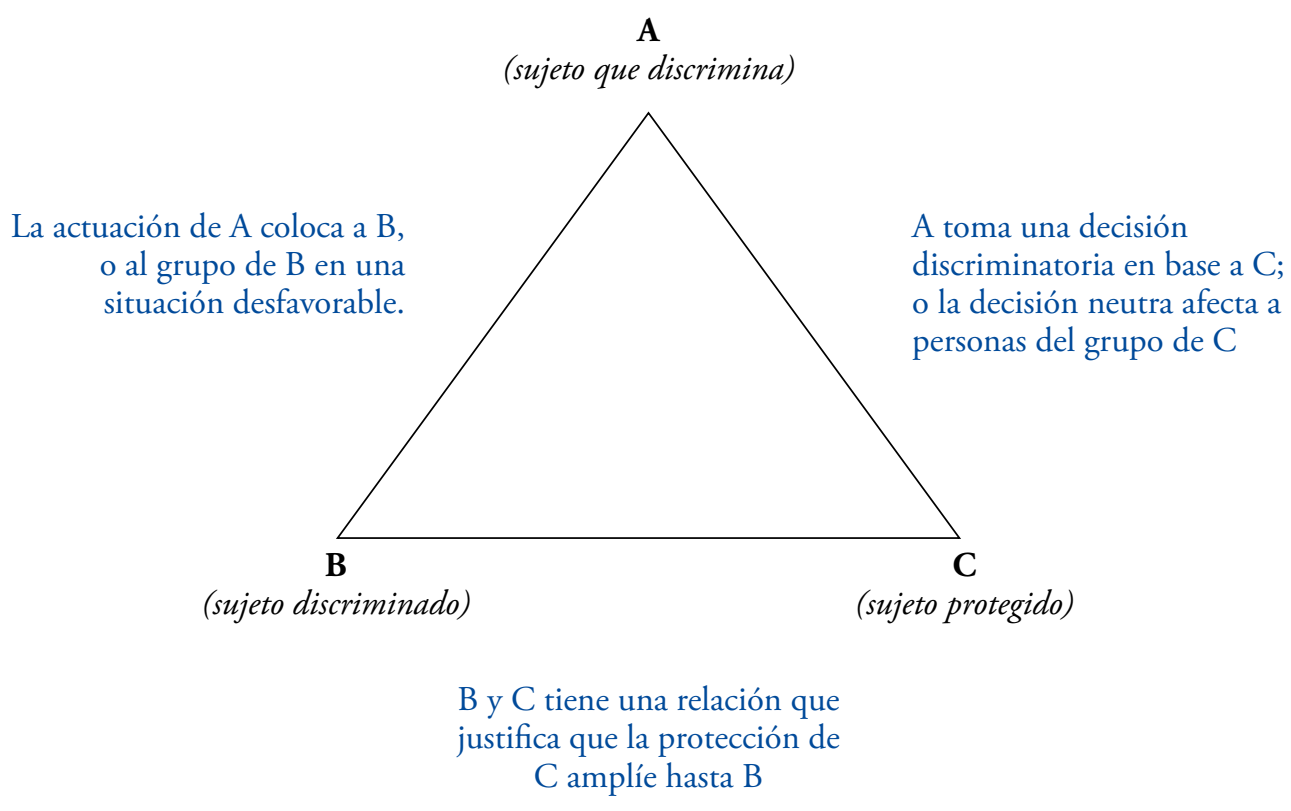

Fuente: elaboración propia

que a quienes sí son parte de dicho colectivo protegido. Es decir, este último está ocupando el lugar que, tradicionalmente, solo estaba reservado a las personas protegidas directamente por la norma por su pertenencia a un colectivo vulnerable porque se ha producido una ampliación de los sujetos amparados por la norma.

La ausencia de definición normativa sobre este tipo de discriminación, pues como hemos visto se trata de una creación jurisprudencial, hace que sus requisitos sean también producto de su aplicación a casos concretos. Se ha visto y repetido a lo largo de este trabajo que su definición ha cambiado y crecido paulatinamente y, tras más de diez años de aplicación por los tribunales, sus elementos han ido clarificándose. La sentencia Coleman, asunto C-303/06 en el año 2008 defendía que la discriminación por asociación era necesaria para que, en el marco de una discriminación por discapacidad, quedasen protegidos también quienes se dedicasen a su cuidado, especialmente si se trataban de sus progenitores. Sobre una relación de vínculos familiares se sentaron las bases de una relación que hoy en día parece haberse liberado de cualquier adjetivo delimitante. El caso Chez Razpredeleine (STJUE de 5 de febrero, C- 83/14) siguiente resolución en el tiempo dictada por el TJUE respecto a este tema, daba un gran salto determinando una posible discriminación por asociación cuando la relación entre los sujetos discriminados y protegidos era tan solo de convivencia en un mismo barrio. En otros supuestos, los más numerosos, se ha visto discriminación por asociación en relaciones familiares como de paternalidad, de conyugalidad o similares (STC 71/2009, STSJ de Canarias, de 29 de agosto de 2019, STS 79/2020). Además, hay también supuestos que han visto discriminación por asociación en relaciones de lo más variadas. Piénsese en la STSJ de Galicia de 2 de agosto donde un trabajor queda protegido por el derecho fundamental a la libertad sindical sin ser el mismo sindicalista; o el caso WTG Retail BVBA C-404/18, donde una trabajadora de una empresa se pronuncia en defensa de una candidata, a quien había entrevistado, ante la decisión de no contratarla por estar embaraza y también queda protegida gracias a la discriminación por asociación que traslada la protección de la mujer embarazada a esta trabajadora. Ni tan si quiera la única 
definición legal de nuestro Ordenamiento jurídico ayuda a clarificar de qué relación estamos hablando, pues el RDLeg tan solo dice "existe cuando una persona o grupo en que se integra es objeto de un trato discriminatorio debido a su relación con otra por motivo o por razón de discapacidad."

La respuesta a la pregunta acerca de qué tipo de relación estamos hablando en una discriminación por asociación, es precisamente la ausencia de adjetivación de esa relación. Lejos de parecer una decisión arbitraria del legislador, me atrevería a insinuar que es algo meditado que abre la puerta a que sean los tribunales quienes se encarguen de definir este tipo de relación. No es casualidad que tan solo aparezca en una norma estatal de esta manera tan laxa, porque de haberlo querido de otro modo el legislador se hubiese preocupado de enumerar las relaciones que han de darse entre los sujetos participes de la discriminación por asociación. La ausencia de regulación nos hace estar ante un numerus apertus de vínculos susceptibles de invocar para defender a una víctima de discriminación por asociación. Desde el año 2008, cuando nace este concepto, hasta la actualidad, la lucha contra la discriminación no se ha detenido y ha habido oportunidades para incluir en la norma una definición más concreta de los elementos de la discriminación por asociación. Pero me atrevería a decir que, si no se ha hecho, no ha sido por falta de ganas; todo lo contrario, si no porque la quintaesencia de esta tipología es su maleabilidad; esto es, su capacidad de adaptación a una infinidad de supuestos.

La definición de discriminación por asociación que podemos elaborar a partir de la que contiene el RDLeg 1/2013 podría resultar algo así: la discriminación por asociación existe cuando una persona, o grupo en que se integra, es objeto de un trato discriminatorio debido a su relación con otra por un motivo o razón protegido. Si definir es limitar, definir qué se entiende por "relación de una persona con otra", probablemente hubiese limitado los supuestos en los que se ha empleado este tipo discriminatorio en ausencia de definición.

No obstante, también habría que considerar aspectos negativos que esta ausencia de definición conlleva. La ambigüedad del concepto da cierta inseguridad jurídica al enjuiciamiento de este derecho, ya que recae mayoritariamente sobre los tribunales el peso de su posible aplicación. Ni las directivas, ni las leyes nacionales, más allá del RDLeg 1/2013 reconocen explícitamente la discriminación por asociación, haciendo que sea la pericia de la parte demandante, o de los órganos enjuiciadores, los responsables de su aplicación. Si bien es cierto que los tribunales se han mostrado abiertos a reconocer discriminación por asociación allí donde ha aparecido, y que en esta línea parece que evolucionaremos en un futuro; la definición de este concepto no traería más que beneficios. Quizás, si se regulasen uno a uno los elementos de la discriminación por asociación serían más fácil su empleo. O quizá, conllevaría el efecto opuesto, excluyendo a supuestos que sí habrían cabido dentro de este tipo.

Cuestión controvertida también es determinar sobre quién recae la obligación de probar esta relación. Dado que la parte demandada es quien tiene la carga de demostrar que su comportamiento no es constitutivo de una discriminación, también debería poder desvirtuar la supuesta relación entre los sujetos discriminado y protegido. No obstante, no siempre es fácil porque el propio significado de la palabra "relación" es subjetivo, y sujeto al juicio de cada persona, por lo que se convierte en una tarea diabólica para la demandada. ¿De qué relación se está hablando? ¿Cómo de cercana ha de ser tal relación? ¿Cómo se prueba una relación? Encontrar unos parámetros objetivos para su definición es algo complicado que el legislador, como venimos diciendo, no ha hecho, y son los tribunales quienes entran a su valoración de acuerdo a su criterio.

Sea como fuere, tras este estudio, podemos afirmar que la indeterminación sobre qué tipo de relación ha de haber entre el sujeto amparado por la norma y el que demanda protección en una discriminación por asociación, ha permitido que se recurra a ella en varias ocasiones, impulsando así su objetivo principal que no es otro que garantizar el principio de igualdad de trato en el ámbito de aplicación de la norma antidiscriminatoria adaptable a cada caso en concreto. 


\section{Conclusiones}

La UE ha elaborado una política social cada vez más completa, donde la igualdad de trato y la prohibición de discriminación ocupan un lugar central. Esto ha contribuido, indudablemente, a que los Estados miembros alcancen unas metas más ambiciosas en aras de acabar con los perjuicios que aún siguen existiendo en el imaginario social y que obstaculizan la consecución de la igualdad efectiva entre todos los ciudadanos.

El TJUE también ha sido, y es, una pieza fundamental en la construcción de este camino, pues ha ampliado el concepto de discriminación que recogían la norma y las Directivas antidiscriminatorias: Directiva 2000/78, Directiva 2000/43 y Directiva 2006/54, hacia nuevos sujetos o nuevos motivos. En este sentido, el asunto Coleman sentaba las bases de la discriminación por asociación. Esta última ha ido evolucionando paulatinamente hasta poder afirmar que se refiere a aquella discriminación que padece una persona, no por padecer una característica protegida por la ley, sino por guardar una relación con una persona que sí la posee. Dado que no se ha desarrollado normativamente, es la practica judicial la que ha ido perfeccionando este concepto. Los Estados miembros, como es el caso de España, influenciados por las decisiones del Alto Tribunal, también han aplicado este concepto contribuyendo a su elaboración. De todo esto pueden extraerse cuáles son los elementos caracterizadores la discriminación por asociación:

(i) Que el supuesto de hecho caiga bajo el ámbito de aplicación de alguna norma que otorgue una tutela antidiscriminatoria

(ii) Que, a consecuencia de un acto u omisión, un sujeto sufra una particular desventaja en una situación comparable con otros sujetos.

(iii) Que dicha práctica, criterio o disposición, haya estado motivado y este íntimamente relacionado con la circunstancia o características personales protegidas en la ley; y que no tenga justificación alguna.

(iv) Que el sujeto que sufre la discriminación no sea la misma persona que padezca o tenga la circunstancia o característica protegida por la ley.

(v) Que exista una relación entre el sujeto perteneciente a un colectivo vulnerable y el sujeto demandante de tutela antidiscriminatoria.

Sin límites, no hay concepto, porque no podríamos definirlo. Para poder aplicar un concepto jurídico como éste es imprescindible cuales son los requisitos que se han de cumplir, porque de otra manera podría desvirtuarse su significado.

Una particularidad de la discriminación por asociación es precisamente que, al no estar regulado en una norma, se permite una mayor maleabilidad. Es decir, que estos cinco elementos delimitadores pueden adaptarse a cualquier situación y ampliar la tutela antidiscriminatoria a los sujetos que así lo requieran, propiciando una tutela frente a posibles vulneraciones de derechos fundamentales que ha de ser considerado favorablemente. Se trata de un tipo de discriminación de creación jurisprudencial que está asumido por nuestro ordenamiento jurídico, aunque se haya reconocido en no muy numerosas ocasiones. No obstante, existe un cierto punto de inseguridad jurídica fruto de la ambigüedad en la interpretación de sus términos, que podría llegar a dar lugar o bien a un desuso del término o a un uso excesivo del mismo, desvirtuando así su esencia. La labor de los tribunales es imprescindible para conocer cuándo hay o no discriminación por asociación, y en todo caso hay que evaluar positivamente la creación de nuevos tipos de discriminación, ya que contribuyen a alcanzar la meta de igualdad efectiva a la que aspira todo Estado de Derecho. 


\section{Bibliografía}

Cabeza Pereiro, Jaime "La discriminación por discapacidad: el caso Chacón Navas", Revista del Ministerio de Empleo y Seguridad Social, n. ${ }^{\circ}$ 102, 2013, Ministerio de Empleo y Seguridad Social, pp. 299-318.

Cabra de Luna, Miguel Ángel; Gaztelu San Pío, Clara "La protección jurídica de las personas con discapacidad en la normativa comunitaria y en los instrumentos internacionales", en Régimen jurídico de las personas con discapacidad en España y en la Unión Europea, Comares, Granada, 2006, pp. 19-93.

Cann, Claude "Court of Justice of the eu Rules Collective and Inaccessible Electrical Metres Discriminate against Roma: chez Razpredelenie Bulgaria ad v. Komisia za zashtita ot diskriminatsia (C-83/14)", European journal of migration and law, vol. 18, n. ${ }^{\circ} 1,2016$, Brill | Nijhoff, Brill Academic Publishers, The Netherlands, pp. 112-125.

Cordero Gordillo, Vanessa "Discriminación por asociación con una persona con discapacidad", Derecho Social, vol. 43, 2008.

El nuevo y cambiante mundo del trabajo. Una mirada abierta y crítica a las nuevas realidades laborales (blog). http://www.eduardorojotorrecilla.es/

Foro de labos (blog), https://forodelabos.blogspot.com/

Lousada Arochena, José. Fernando., El enjuiciamiento de género, Dykinson, 2020.

Lousada Arochena, José Fernando "La prueba de la discriminación en el derecho comunitario", Revista de derecho social, n. ${ }^{\circ}$ 60, 2012, Bomarzo, pp. 125-138.

Mangas Martín, Araceli., Instituciones y Derecho de la Unión Europea, 10ª ed., : Tecnos, Madrid, 2020.

Muñoz Ruiz, Ana Belén, "El caso Coleman: un paso más en la construcción del modelo social de discapacidad de la Unión Europea y su extensión a los cuidadores", Temas laborales: Revista andaluza de trabajo y bienestar social, n. $^{\circ}$ 101, 2009, Consejo Andaluz de Relaciones Laborales, pp. 321-339.

Nieto Rojas, Patricia "Nuevas manifestaciones de la protección del embarazo en la doctrina del Tribunal de Justicia de la Unión Europea: Comentario a la Sentencia del Tribunal de Justicia de la Unión Europea de 20 de junio de 2019, asunto C-404/18, Hakelbracht”, 2019.

Pilgerstorfer, Marcus; Forshaw, Simon "Transferred Discrimination in European Law: Case C-303/06, Coleman v Attridge Law; [2008] ICR 1128, [2008] IRLR 722 (ECJ)”, Industrial Law Journal, vol. 37, n. ${ }^{\circ}$ 4, 2008, pp. 384-393.

Razabi, Shahra ; StaAb, Silke "Mucho trabajo y poco salario. Perspectiva internacional de los trabajadores del cuidado", Revista internacional del trabajo, vol. 129, n. ${ }^{\circ} 4,2010$, Blackwell Publishing Ltd, Oxford, UK, pp. 449-467.

Rodríguez Rodríguez, Emma "La prohibición de discriminación por asociación o vinculación respecto del derecho a la libertad sindical", Revista General de Derecho del Trabajo y de la Seguridad Social, n. ${ }^{\circ} 48,2018$, Iustel, p. 9.

Langa Rosado, Delia "La influencia de la clase social y el género en el familismo y la mercantilización del trabajo de cuidado en los hogares", RIEM. Revista internacional de estudios migratorios, vol. 4, n. ${ }^{\circ}$ 2, 2017, pp. 207-230.

Stewart, Ann; Niccolai, Silvia; Hoskyns, Catherine, "Disability Discrimination by Association: A Case of the Double Yes?”, Social \& legal studies, vol. 20, n. ${ }^{\circ}$ 2, 2011, SAGE Publications, Sage Publications, Inc, London, England, pp. 173-190.

Velasco Portero, María Teresa "Doctrina del TJ sobre discriminación por asociación y su impacto en nuestra jurisprudencia”, Revista Galega de Dereito Social - 2a etapa: (RGDS), 9, 2019, Consello Galego de Relacións Laborais. 